\title{
Right Ventricular Rupture in Redo Coronary Artery Bypass Grafting
}

\author{
Zihou Liu, MD, Chao Chang, MD, Jiapeng Liu, MD, Qiang Wang, MD \\ Department of Cardiac Surgery, Tianjin Chest Hospital, Tianjin, China
}

\section{ABSTRACT}

A 71-year-old man presented to us with recurrent chest pain, which led to cardiac catheterization. He was a strong candidate for redo coronary artery bypass grafting (CABG). CT was performed to confirm whether the heart was adherent to the sternum and chest wall. For safety reasons, cardiopulmonary bypass $(\mathrm{CPB})$ was first performed via right femoral cannulation before sternotomy. After the spontaneous right ventricular (RV) rupture, HTK was used to arrest the heart. Heart repair materials were applied to repair the fissure of RV to avoid further tearing and bleeding. A compromise scheme was adopted when it was found to be difficult to identify and expose well the target artery, due to severe adhesion. This was done to avoid possible severe consequences of further dissection of the heart. Intraoperative transesophageal echocardiography (TEE) was used to evaluate the cardiac function, and intra-aortic balloon pump (IABP) support was applied in time. In consideration of the RV enlargement, which TEE revealed may have been caused by myocardial edema and cardiac insufficiency, modified ultrafiltration was performed, and a timely decision of open chest management (OCM) with delayed sternal closure (DSC) was made to maintain hemodynamic stability. The patient had no further complications and eventually recovered well, according to a 4-month follow up.

\section{INTRODUCTION}

Right ventricular rupture is a rare but challenging and potentially lethal complication that can occur in cardiac surgery. A repeat sternotomy largely increases the risk of ventricle rupture [Doody 2018]. Coronary artery bypass graft (CABG) surgery is the reference standard treatment and preferred revascularization strategy of cardiovascular disease [Maltais 2017]. Redo CABG is a technically challenging and demanding procedure for the surgeon and is associated with an increased risk of major complications [Takahashi 2013]. In this report, the authors describe a case of right ventricular (RV) rupture occurring in redo CABG.

Received fuly 1, 2020; accepted fuly 10, 2020.

Correspondence: Zibou Liu, MD, Department of Cardiac Surgery, Tianjin Chest Hospital, Tianjin, China (e-mail: drliuzihou@botmail.com), or Qiang Wang, MD, Department of Cardiac Surgery, Tianjin Chest Hospital, No.261 Taierzhuang South Road, Finnan District, Tianjin, 300222 China; 008618002093077, fax: 0086-22-88185078 (e-mail: drwangqiangtj@163.com).

\section{CASE REPORT}

A 71-year-old man presented to us with a two-month history of recurrent chest pain. His medical history included hypertension, hyperlipidemia, diabetes, and known coronary artery disease. Twelve years before, he underwent triple-vessel off-pump CABG with left internal mammary artery (LIMA) to the left anterior descending (LAD) artery, and saphenous vein graft (SVG) to the posterior descending (PDA) artery and the first diagonals artery (Diag). Twelve years later, recurrent symptoms led to a cardiac catheterization, which revealed proximal segment, middle segment and distal segments of the LAD artery with $99 \%, 90 \%$ and $99 \%$ stenosis, respectively; total occlusive PDA; and stenosis of more than $90 \%$ in the distal segments in LIMA to LAD, middle segment in SVG to PDA, and proximal segment in SVG to Diag. A percutaneous intervention was not clinically possible, and surgical intervention was recommended.

The patient underwent an initial clinical assessment. By color Doppler transthoracic echocardiography (TTE), the right ventricular basal diameter was $39 \mathrm{~mm}$, left ventricle enddiastolic dimension as measured in the short axis view was 54 $\mathrm{mm}, \mathrm{LV}$ ejection fraction was $48 \%$, and systolic pulmonary artery pressure (PAP) was $30 \mathrm{mmHg}$. Computed tomography (CT) showed an intimate contact of the heart with the sternum. (Figures $1 \mathrm{~A}$ and $1 \mathrm{~B}$ ).

For safety reasons, cardiopulmonary bypass (CPB) was first performed via right femoral cannulation. A median sternotomy was then performed with a standard oscillatory saw. Great saphenous vein (SV) was harvested under endoscopic. However, the adhesions were so severe and firm, especially contact of the RV with the sternum, as the CT revealed. Dissection of the heart, ascending aorta, and grafts were carefully performed. Unfortunately, the RV still ruptured from the anterior wall contact with the sternum. Superior vena cannulation was additionally performed. Cardiac arrest was immediately achieved using antegrade 2000ml Custodiol® HTK (KÖHLER, Germany). Exploration of the mediastinum revealed a significant tear of the RV free wall measuring $50 \mathrm{~mm}$.

Redo on-pump CABG was performed with SV grafts (SVGs) to the LAD, PDA, and Diag. SVG to LDA easily was achieved. However, it was challenging to find an optimal anastomotic site in the PDA and Diag. Considering the patency and free of significant arteriosclerosis of the distal segment of bypass grafts (original SVG to PDA and original SVG to Diag), the distal anastomotic sites (new SVG to PDA and new SVG to Diag) were chosen at the distal segment of original SVGs closing to the target artery as Y grafts (Figure 

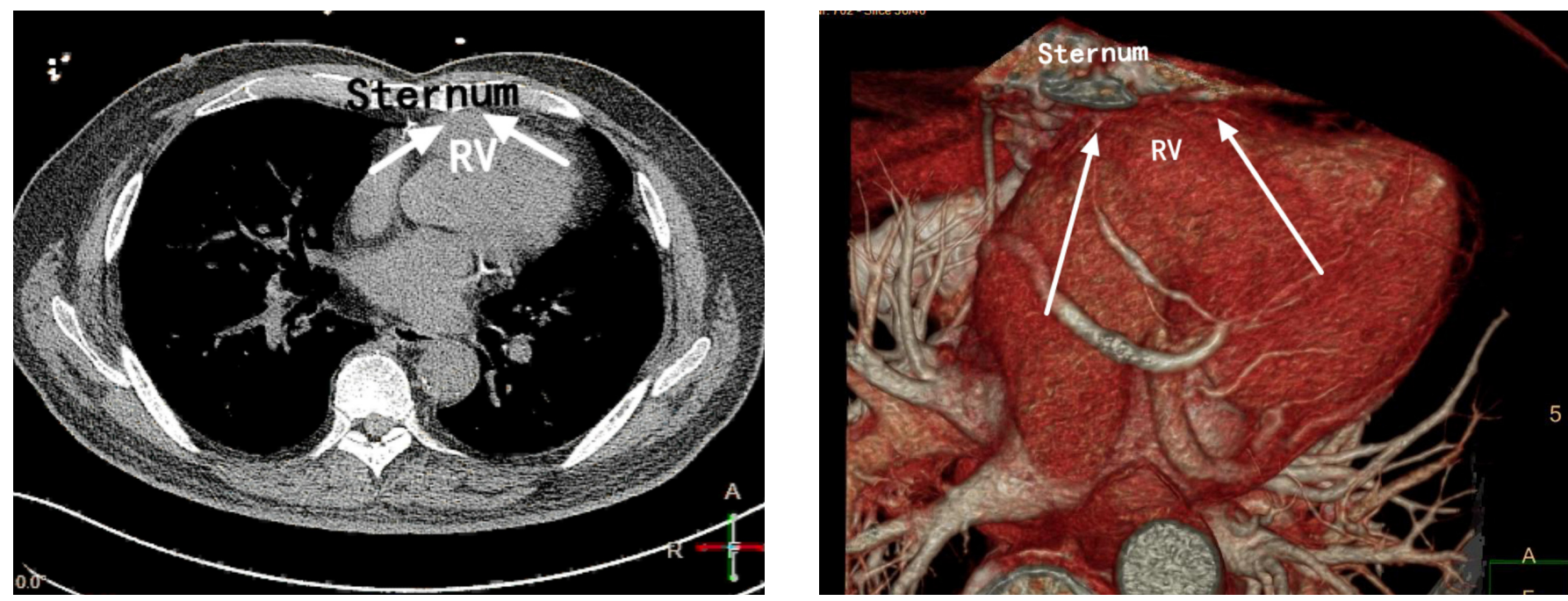

Figure 1. A, CT and 3D reconstruct showing an intimate contact of the heart with the sternum (white arrow). CT, computer tomography. B, CT and 3D reconstruct showing an intimate contact of the heart with the sternum (white arrow). $\mathrm{CT}$, computer tomography.

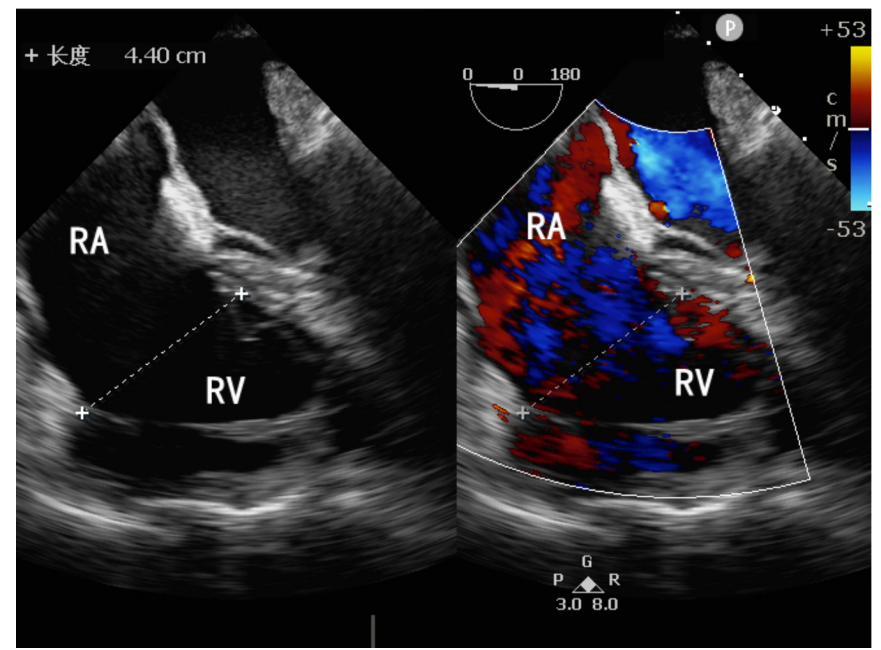

Figure 2. TEE showing right ventricular enlargement. TEE, transesophageal echocardiography.

1B). The proximal anastomosis (LAD and PDA) was anastomosed to the aorta, and the proximal of Diag was anastomosed to the proximal segment in SVG LAD as a Y graft. We then patched the RV with Dacron (CHEST, China) strips, which were placed parallel to the defect, and five horizontal mattress sutures of 3-0 polypropylene were put through the full thickness of the ventricular wall and through the strips.

The patient could not wean from cardiopulmonary bypass (CPB) without the support of high doses of vasoactive agents. Transesophageal echocardiography (TEE) revealed a dysfunction in the left ventricle (LV), an increased PAP, and significantly enlarged RV (Figure 2). Cardiac insufficiency was considered, and intra-aortic balloon pump (IABP) was inserted through a femoral artery. The patient was weaned from CPB, and modified ultrafiltration was performed. However, when the sternum was closed, the heart rate reached 130 beats/ minute, CVP would increase to $35 \mathrm{mmHg}$, blood pressure could be reduced to $60 / 40 \mathrm{mmHg}$, and TEE showed limited diastolic function. Given the sternal compression, the sternum was again reopened, and there was marked improvement in his hemodynamics. The decision of delayed sternal closure (DSC) was made. Given the possibility of compression and damage to the heart by the sternum, three $\mathrm{CPB}$ pipe joints were used for opening the sternum, and the joints were fixed by the Ti-Cron ${ }^{\mathrm{TM}}$ 30" sutures (COVIDIEN, USA) (Figure $3 \mathrm{~A})$. A piece of surgery film was sewn to the skin edge and covered the surgical incision to achieve sterile mediastinal isolation (Figure 3B). Two standard mediastinal drains were used to ensure satisfactory drainage. The patient was mechanically ventilated and appropriately sedated in the intensive care unit. Broad spectrum antibiotic prophylaxis was maintained. Three days later, the patient's hemodynamics were stable without vasoactive agent support. Sternal closure then was smoothly performed. The patient had no further complications and eventually recovered well, according to a 4-month follow up.

\section{DISCUSSION}

$\mathrm{RV}$ rupture commonly is associated with myocardial infarction [Arat 2007; Dandeniya 2020], cardiopulmonary resuscitation [Hickey 2016; Sokolove 2002], trauma [Chan 2007], cardiac surgery [Ono 1998; Swaminathan 2003], and mediastinitis after sternotomy [Doody 2018; Suen 1998]. A repeat sternotomy more than two weeks after the initial operation is associated with an increased risk of ventricle rupture because the surface of the heart may become extensive and densely adherent to the sternum, pericardium, and pleural [Doody 2018]. Dissection of the heart is needed, which may lead to catastrophic consequences and even death [Weyrauch 2020; Doody 2018]. 

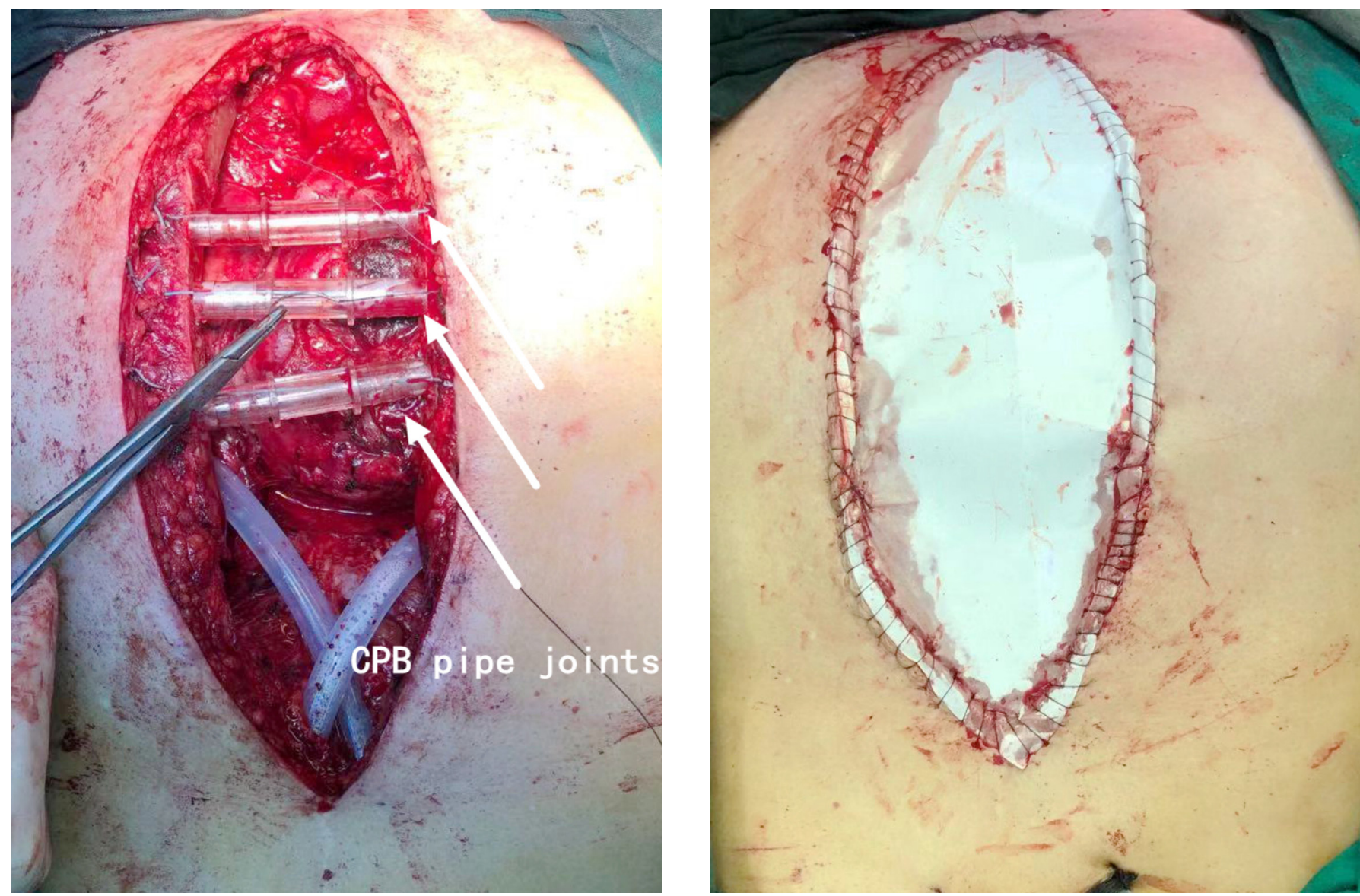

Figure 3. A, Three CPB pipe joints being used for opening the sternum, and the joints being fixed by the Ti-Cron ${ }^{\text {TM } 30 " ~ s u t u r e s ~(w h i t e ~ a r r o w) . ~ C P B, ~ c a r d i o-~}$ pulmonary bypass. B, A piece of surgery film being sutured to cover the surgical incision.

Owing to an inevitable degeneration of grafts over time, patients may require consideration for repeat CABG surgery [Maltais 2017]. By 10 years, $50 \%$ to $60 \%$ of SV grafts may be patent, and half of these are free of angiographic arteriosclerosis [Sabik 2013]. Previous studies have described redo CABG is more challenging than the first CABG in many aspects, such as access to the heart with potential for cardiac injury, identification and management of patent grafts without harming them, availability of conduit material, and difficulty with finding and exposing target vessels [Rufa 2019; Bruno 2017].

Post-cardiotomy open chest management (OCM) with subsequent DSC is an important intervention for patients, who are unable to undergo sternal closure after cardiac surgery. It relieves cardiac compression, improves patient hemodynamic parameters, and improves perioperative critical care with a resultant increase in survival rates [Wong 2017; Boeken 2011].

In our own patient, redo $\mathrm{CABG}$ was strongly indicated because he had three graftable coronary arteries whose territory were ischemic and viable, and he was symptomatic. Extreme thinning and dilatation of the RV may be related to long-standing myocardial ischemia caused by coronary artery and bypass grafts stenosis. CT was first performed to confirm whether the heart was adherent to the sternum or chest wall [Bruno 2017; Ghanta 2013].

Intraoperatively, given the severe adhesions, $\mathrm{CPB}$ was performed via right femoral cannulation. Although RV rupture suddenly happened, there was a good chance for further rescue because it was during CPB. While dissecting the adhesions, we speculate that the RV epicardium was injured, and the RV suffered mechanical stress to some degree because of the need for exposure. Also, the RV free wall was extremely thin. In retrospect, the simple technique of covering the RV during the cardiac operation, which can directly prevent contacting the heart with the sternum [Flege 1987], was ignored at the first CABG. The safest approach to the prevention of injury to structures adherent to the sternum should be referred and taken [Black 2014].

Heart repair materials were applied to the rupture of the RV [Suen 1998] to avoid further tear and bleeding. A compromise scheme was adopted [Tribble 2018], when it was found to be difficult to identify and expose well the target artery, due to the severe adhesions, avoiding possible severe consequences of further dissection of the heart. Intraoperative TEE was used to monitor and evaluate the cardiac function, and IABP support was applied in time. In consideration of the RV enlargement, which TEE revealed may be caused by 
myocardial edema and cardiac insufficiency, modified ultrafiltration was performed, and a timely decision of OCM with DSC was made to maintain hemodynamic stability [Wong 2017; Shalabi 2002].

This case emphasizes the importance of the appropriate approach to the RV, which was known to be adherent to the sternum. It also emphasizes the need to cover the RV in each cardiac operation, which would serve the interest of future patients and the surgeons who care for them, as well as the need for constant and multiple methods of monitoring and evaluation of hemodynamics and cardiac functional status during operation.

\section{ACKNOWLEDGEMENT}

This work was supported by Science and Technology Funding of Tianjin Chest Hospital [grant numbers 2018XKZ14] and Science and Technology Fund of Tianjin Municipal Health Bureau [grant numbers 2014KY32].

\section{REFERENCES}

Arat N, Sökmen Y, Ilkay E. 2007. Isolated right ventricular rupture: a rare complication of myocardial infarction. Acta Cardiol. 62(4): 413-6.

Black A, Alexander JA, Reoma J, et al. 2014. Safe sternal reentry in patients with large thoracic aortic pseudoaneurysms. Ann Thorac Surg. 97(2): 705-7.

Boeken U, Assmann A, Mehdiani A, Akhyari P, Lichtenberg A. 2011. Open chest management after cardiac operations: outcome and timing of delayed sternal closure. Eur J Cardiothorac Surg. 40(5): 1146-50.

Bruno VD, Zakkar M, Rapetto F, et al. 2017. Early health outcome and 10 -year survival in patients undergoing redo coronary surgery with or without cardiopulmonary bypass: a propensity score-matched analysis. Eur J Cardiothorac Surg. 52(5): 945-951.

Chan V, Klug AP, Bedard P, Burwash IG. 2007. Traumatic right ventricular rupture. Eur J Cardiothorac Surg. 32(1): 163.

Dandeniya Arachchi S, Ruwanpura R. 2020. A rare case of post-infarction right ventricular rupture. Cardiovasc Pathol. 47: 107203.

Doody R, Cronin B, O'Brien EO. 2018. Right Ventricular Rupture After Extubation of a Patient With an Open Chest. J Cardiothorac Vasc Anesth. 32(1): 461-463.
Flege JB Jr. 1987. Pericardial incision for internal mammary artery coronary bypass. Ann Thorac Surg. 44(4): 424.

Ghanta RK, Kaneko T, Gammie JS, Sheng S, Aranki SF. 2013. Evolving trends of reoperative coronary artery bypass grafting: an analysis of the Society of Thoracic Surgeons Adult Cardiac Surgery Database. J Thorac Cardiovasc Surg. 145(2): 364-72.

Hickey TB, Gill GG, Seidman MA, Webber DL. 2016. CPR-associated right ventricular rupture in the setting of pulmonary embolism. CJEM. 18(6): 484-487.

Maltais S, Widmer RJ, Bell MR, et al. 2017. Reoperation for Coronary Artery Bypass Grafting Surgery: Outcomes and Considerations for Expanding Interventional Procedures. Ann Thorac Surg. 103(6): 1886-1892.

Ono M, Takamoto S, Ohtsuka T. 1998. Right ventricular rupture in minimally invasive direct coronary artery bypass grafting. Eur J Cardiothorac Surg. 14(5): 536-7.

Rufa MI, Ursulescu A, Nagib R, et al. 2019. Off-pump versus on-pump redo coronary artery bypass grafting: A propensity score analysis of longterm follow-up. J Thorac Cardiovasc Surg.

Sabik JF 3rd, Raza S, Blackstone EH, Houghtaling PL, Lytle BW. 2013. Value of internal thoracic artery grafting to the left anterior descending coronary artery at coronary reoperation. J Am Coll Cardiol. 61(3): 302-10.

Shalabi RI, Amin M, Ayed AK, Shuhiber H. 2002. Delayed sternal closure is a life saving decision. Ann Thorac Cardiovasc Surg. 8(4): 220-3.

Sokolove PE, Willis-Shore J, Panacek EA. 2002. Exsanguination due to right ventricular rupture during closed-chest cardiopulmonary resuscitation. J Emerg Med. 23(2): 161-4.

Suen HC, Barner HB. 1998. Repair of right ventricular rupture complicating mediastinitis. Ann Thorac Surg. 66(6): 2115-6.

Swaminathan M, Kypson AP, Perna JG, Davis RD, Stafford-Smith M. 2003. Right ventricular rupture during off-pump coronary bypass surgery. J Cardiothorac Vasc Anesth. 17(1): 87-9.

Takahashi M, Rhee AJ, Filsoufi F, Silvay G, Reddy RC. 2013. Anesthetic and technical considerations in redo coronary artery bypass surgery using sternal-sparing approaches. J Cardiothorac Vasc Anesth. 27(2): 315-8.

Tribble CG. 2018. Reoperative Cardiac Surgery - Part II. Heart Surg Forum. 21(2): 124-31.

Weyrauch D, Kemp WL, Koponen M. 2020. Right Ventricle Rupture After Open Heart Surgery. Am J Forensic Med Pathol. 41(1): 35-39.

Wong JK, Joshi DJ, Melvin AL, et al. 2017. Early and late outcomes with prolonged open chest management after cardiac surgery. J Thorac Cardiovasc Surg. 154(3): 915-924. 